\title{
An Implementation of Integrated Interfaces for Telecom Systems and TMS in Vessels
}

\author{
Jungwoo Kim, Jooyoung Son, and Kyoungkuk Yoon
}

\begin{abstract}
Today, ship related technology development and research are actively carried out. With the development of telecom systems, ships and offshore plants can be managed and controlled from any location on the planet. Major applications are smart ship, optimal ship routing, and unmanned vessel, all of which are upgrading based on telecom systems. In the first place, telecom systems served as tools for long-distance communication, but now they include all systems related to data or information. Still, however, telecom systems are not standardized due to regulatory and financial limitations. A ship installs a complex ensemble of countless cables and equipment for the interface of its telecom systems. And since new ship technologies are solely focused on sharing with existing systems, they continue to add cables and equipment. Like this, half-finished ship technology only adds to vessel weight and increases the costs for design and maintenance and repair. Telecom systems should be standardized to steer clear of the need for physical expansion, while systematic management should be ensured by introducing standard management systems like TMS. This paper proposes a method to realize integrated interface for telecom systems and TMS.
\end{abstract}

Index Terms - TMS, telecom, vessel, interface.

\section{INTRODUCTION}

Today, systems of vessels are continuously increasing. In particular, telecom systems are increasing more as the management method of information exchange and the development of technology with the land. Past telecom systems for vessels did not incorporate data sharing through interface. As digital began to be applied to vessels, telecom systems began to share their data. All vessel data is delivered to telecom systems and is controlled with them. The scope of ship management is decided by how telecom systems are organized. Looking ahead, telecom systems will be the most important factor that determines the performance of a vessel [1].

The next-generation vessels will be managed and controlled together on land. For the safety of vessels, telecom systems shall be mandatory equipment by maritime treaties such as the IMO(International Maritime Organization). However, the IMO does not amend the vessel's telecom systems.

Manuscript received January 19, 2017; revised May 19, 2017.

Jungwoo Kim is with Department of Power Control \& Automation Design, Hyundai Heavy Industries Co., Ltd., Ulsan, Korea (e-mail: kimjungwoo@hhi.co.kr).

Jooyoung Son is with Division of Marine IT Engineering, Korea Maritime and Ocean University, Busan, Korea (e-mail: mmlab@kmou.ac.kr).

Kyoungkuk Yoon is with Department of R\&D Center, Seanet Co., Ltd., Busan, Korea (e-mail: kkyoon@sea-net.co.kr).
It is difficult to develop and apply new technology for telecom systems of vessels. Technological development is sluggish even for legally mandatory equipment. 1974 SOLAS(International Convention for Safety of Life at Sea), which is the standard for ship safety, provides only for navigation and some of radio equipment [2]. Despite partial revisions that took place in early 2000 , there were almost no big changes [3]. Thus, a convention written several decades ago remains detrimental to the technological development for today's telecom systems.

Therefore, NORSOK defined content for the management of telecom systems [4]. As a result, offshore plants are increasing aware that telecom systems are important for management.

For ships, currently, when installing a new systems on vessels does not take into consideration its integration or compatibility with existing telecom systems. New systems require the installation of additional cables and equipment for data conversion. This is because telecom systems and data are not standardized. In that case, it is hard to apply TMS(Telecommunication Management System) and thereby management telecom systems. Currently, interface design for telecom systems is not improved for all vessels including marine plants.

The paper conducts a test to demonstrate a method to realize an integrated interface for TMS and telecom systems for ships and the reason that data standardization is necessary.

\section{INTRODUCTION OF TMS AND TELECOM SYSTEMS}

\section{A. TMS}

In the 1990s, TMS was first defined by NORSOK, the Norwegian maritime standards [5], [6]. TIU(Telecommunication Interface Unit) are installed per telecom systems to monitoring alerts generated from the telecom systems of offshore plants. TIU serves to convert alerts generated from telecom systems to a data type fit for TMS server. The TMS structure as suggested by NORSOK T-100 is a server/client structure that is based on LAN and WAN as in Fig. 1.

To create TMS, both cables and TIU fit for data type have to be installed for different telecom systems. TMS was a method for interoperability between Telecom systems, but it increased installation cost and complexity. As TMS hasn't defined and standardized telecom systems, it fails to expand to ships and all offshore plants.

\section{B. Telecom Systems}

A telecom system was past one-dimensional method of 
communication. However, recently telecom systems have been integrated with IT(Information technology) and scope and boundary of telecom systems are meaningless.

Generally, for vessels, the communications system and the navigation system are combined and called telecom systems.
Table I shows the scope of telecom systems for vessels, which comprises navigation system, internal communications system, ship-to-ship communications system, and safety management system and they are divided into total 46 systems [7]-[10].

TABLE I: A LIST OF TELECOM SYSTEMS IN VESSELS

\begin{tabular}{|c|c|c|c|}
\hline Seq. & System & Mandatory & Regulation \\
\hline 1 & VSAT(Very Small Aperture Terminal) & $\mathrm{X}$ & \\
\hline 2 & DGPS(Differential Global Positioning System) & $\mathrm{O}$ & SOLAS Reg. V/19 \\
\hline 3 & INS(Integrated Navigation System) & $\mathrm{O}$ & SOLAS Reg. V/19 \\
\hline 4 & Satellite (C \& F) & $\mathrm{O}$ & SOLAS Reg. IV/10 \\
\hline 5 & Auto Pilot & $\mathrm{O}$ & SOLAS Reg. V/24 \\
\hline 6 & Gyro Compass & $\mathrm{O}$ & SOLAS Reg. V/19 \\
\hline 7 & Magnetic Compass & $\mathrm{O}$ & SOLAS Reg. V/19 \\
\hline 8 & Speed Log & $\mathrm{O}$ & SOLAS Reg. V/19 \\
\hline 9 & RAI(Rudder Angle Indicating) & $\mathrm{O}$ & SOLAS Reg. V/19 \\
\hline 10 & Echo Sounder & $\mathrm{O}$ & SOLAS Reg. V/19 \\
\hline 11 & VDR(Voyage Data Recorder) & $\mathrm{O}$ & SOLAS Reg. V/20 \\
\hline 12 & Sound Reception & $\mathrm{O}$ & SOLAS Reg. V/19 \\
\hline 13 & AIS(Automatic Identification System) & $\mathrm{O}$ & SOLAS Reg. V/19 \\
\hline 14 & Clock & $\mathrm{X}$ & \\
\hline 15 & SPT(Sound Powered Telephone) & $\mathrm{O}$ & SOLAS Reg. V/19 \\
\hline 16 & Communal Aerial & $\mathrm{X}$ & \\
\hline 17 & Weather FAX & $\mathrm{O}$ & SOLAS Reg. V/5 \\
\hline 18 & NAVTEX & $\mathrm{O}$ & SOLAS Reg. IV/7 \\
\hline 19 & Marine Radar & $\mathrm{O}$ & SOLAS Reg. V/19 \\
\hline 20 & SSAS(Ship Security Alert System) & $\mathrm{O}$ & SOLAS Reg. XI-2/6 \\
\hline 21 & GMDSS(Global Maritime Distress and Safety System) & $\mathrm{O}$ & SOLAS Reg. IV/10 \\
\hline 22 & LAN Network & $\mathrm{X}$ & \\
\hline 23 & VHF & $\mathrm{O}$ & SOLAS Reg. III/6, Reg. IV/7 \\
\hline 24 & $\mathrm{UHF}$ & $\mathrm{X}$ & \\
\hline 25 & Telephone & $\mathrm{X}$ & \\
\hline 26 & BNWAS(Bridge Navigational Watch Alarm System) & $\mathrm{O}$ & SOLAS Reg. V/18 \\
\hline 27 & Whistle & $\mathrm{O}$ & $\begin{array}{c}\text { COLREG } 72 \text { Annex III/3, } \\
\text { LSA Code MSC.48(66) }\end{array}$ \\
\hline 28 & CCTV(Closed Circuit Television) & $X$ & \\
\hline 29 & Entertainment & $\mathrm{X}$ & \\
\hline 30 & Cinema & $\mathrm{X}$ & \\
\hline 31 & Collaboration & $\mathrm{X}$ & \\
\hline 32 & Meteorological Observation & $\mathrm{X}$ & \\
\hline 33 & MDF(Main Distribution Frame) & $\mathrm{X}$ & \\
\hline 34 & UPS(Uninterrupted Power Supply) & $\mathrm{X}$ & \\
\hline 35 & Helicopter Monitoring & $\mathrm{X}$ & \\
\hline 36 & Wireless Network & $\mathrm{X}$ & \\
\hline 37 & PAGA(Public Address and General Alarm) & $\mathrm{O}$ & SOLAS Reg. III/6 \\
\hline 38 & Talkback & $\mathrm{X}$ & \\
\hline 39 & Elevator Alarm & $\mathrm{X}$ & \\
\hline 40 & Refrigerator Chamber Alarm & $\mathrm{X}$ & \\
\hline 41 & Hospital Calling Alarm & $\mathrm{X}$ & \\
\hline 42 & Satellite TV & $\mathrm{X}$ & \\
\hline 43 & Window Wiper & $\mathrm{X}$ & \\
\hline 44 & Heated Glass & $\mathrm{X}$ & \\
\hline 45 & ADCP(Acoustic Doppler Current Profiler) & $\mathrm{X}$ & \\
\hline 46 & TMS(Telecommunication Management System) & $\mathrm{X}$ & \\
\hline
\end{tabular}

Table I has 22 mandatory systems, which account for $47.8 \%$ of which are mostly designated by SOLAS. However, in the case of VSAT, LAN or etc., it is not defined by maritime treaties despite the necessary systems in vessels. In 
other words, more than $50 \%$ of telecom systems can be installed without verification process and combined with vessel's management system, which can be dangerous.

It is clearly problematic to define today's telecom systems with previously defined maritime treaties and classification. For their standardization, telecom systems with reflected current technology have to be researched, developed, and enforced jointly by maritime treaties, classification and manufacturers.

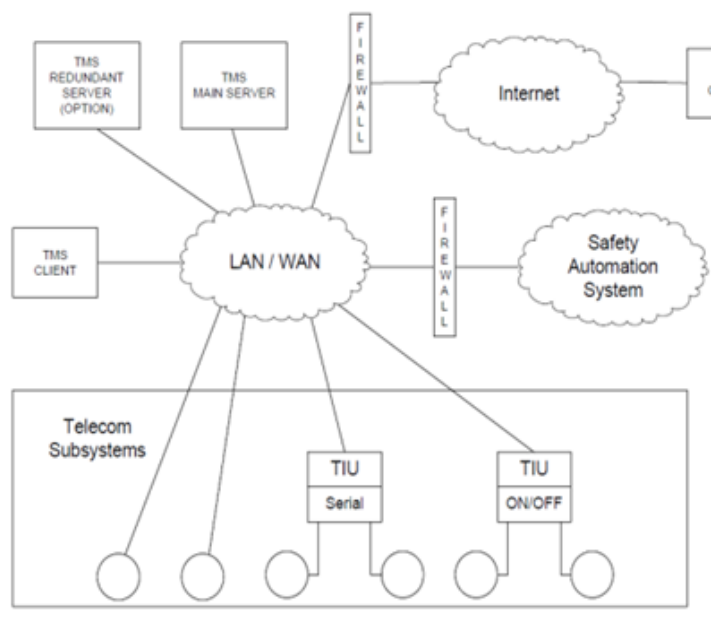

Fig. 1. Schematic diagram of TMS as NORSOK T-100.

\section{ANALYSIS OF INTERFACES AND STANDARDIZATION}

The interface to the vessel's telecom systems includes the role of life protection and asset management, not just data exchange. Telecom systems are all synchronized and batch processed by the interface.

Furthermore, vessels will have an increasing number of new systems, while existing systems will have increases interfaces for expanded functions. Therefore, there will be sharply increased interface among all vessel systems including telecom systems.

It is necessary to confirm whether the current vessel's interface is ready for future expansion. Fig. 2 shows the results of analyzed the interfaces between telecom systems as shown on Table I and related systems for VLCC(Very Large Crude Carrier) vessel.

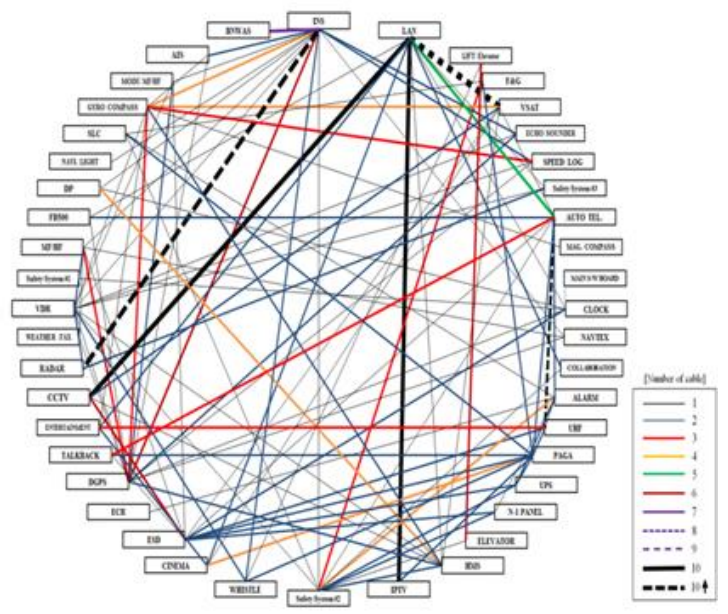

Fig. 2. Diagram for existing interfaces in telecom systems.
In Fig. 2, connections to the same system as the internal connections of telecom systems and connections for the same system were excluded from the analysis. Meanwhile, it did not distinguish the types of cables and the number of cores among different telecom systems. Data types were mainly using Dry Contact, Wet Contact, RS-232, and Analog Output.

Through this analysis show that identified the complex interface of telecom systems in vessels. All telecom systems had interface. Telecom systems required more installed cables to support different data types. We figured out why design and maintenance and repairs were difficult. The problems will continue to repeat unless this problem is improved. If the interface with other systems is included, the complexity increases even more.

Proposed integrated interface structure is similar to that of NORSOK-TMS. However, integrated interface can monitoring, control and transmission all of Alarms. Telecom systems are connected to Interface Unit with one cable. Since all telecom systems use the same standardized data type, there is no delay in the processing time. With syncing becomes possible for the whole telecom systems, real-time data analysis is possible. This paper proposes a method for implementation an integrated interface as shown in Fig. 3, for the purpose of standardizing telecom systems on vessels.

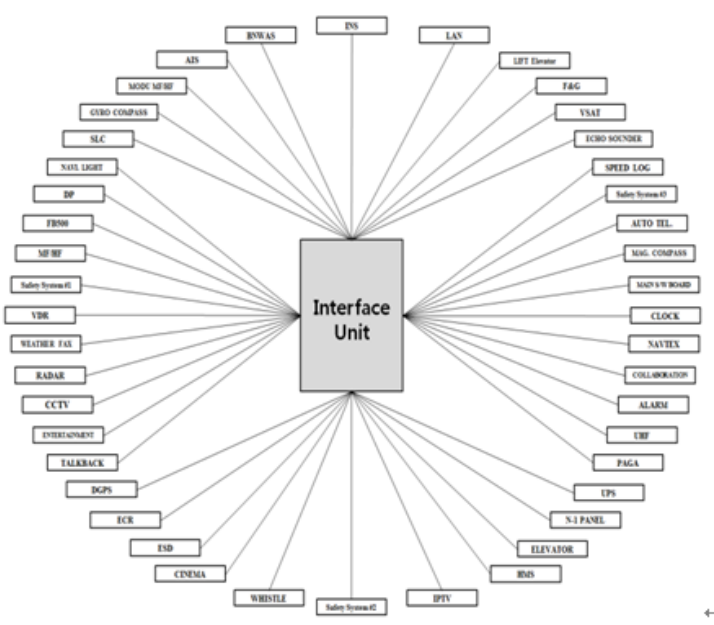

Fig. 3. Diagram for integrated interfaces in telecom systems.

Proposed integrated interface uses central control. Interface Unit processes data from telecom system at 1:M, M:M. Interface unit controls all data and minimizes data redundancy.

Integrated interfaces to obtain reduction such as Table II compared to existing interfaces.

TABLE II: ANALYSIS OF REDUCTION BETWEEN EXISTING INTERFACES AND PROPOSED INTEGRATED INTERFACES

\begin{tabular}{lccc}
\hline \hline Division of cable & $\begin{array}{c}\text { Existing } \\
\text { interfaces }\end{array}$ & $\begin{array}{c}\text { Integrated } \\
\text { interfaces }\end{array}$ & Reduction(\%) \\
\hline Quantity(EA) & 173 & 44 & 74.6 \\
Weight(Ton) & 4.2 & 1.3 & 69.1 \\
\hline \hline
\end{tabular}

In addition to cable, the cable cost reduction of vessels is effective in cost reducing design, production, and inspection.

Proposed integrated interface for telecom systems is 
based on the use of standard data type. Standardization of data should not cause processing time delay. Therefore, this paper proves that the standardization of data is also excellent in the processing time through the test of the following chapter.

\section{Performance Evaluation}

\section{A. Test Environment and Methods}

The data types which are used in the existing telecom systems are Analog Output, RS-232, Wet Contact, and Dry Contact. Because telecom systems are different method of management for each manufacturers. This paper proposes TCP/IP, an internet network protocol, as standard data type for proposed integrated interfaces. Table III shows the data types for the test.

TABLE III: DEFINED LIST OF DATA

\begin{tabular}{llll}
\multicolumn{4}{l}{ TABLE III: DEFINED LIST OF DATA } \\
\hline \hline Division & Data Type & Alarm & Note \\
\hline I/O Module & AO & - System Normal & Existing \\
Serial & RS-232 & - System Abnormal & Existing \\
Wet contact & 25VDC with & Existing \\
Dry contact & Relay & & Existing \\
Ethernet & Relay & & Proposed \\
\hline \hline
\end{tabular}

This paper creates existing interfaces structure and its proposed integrated interface structure to make a comparative analysis of the processing time for different data types as shown in Fig. 4 and Fig. 5.

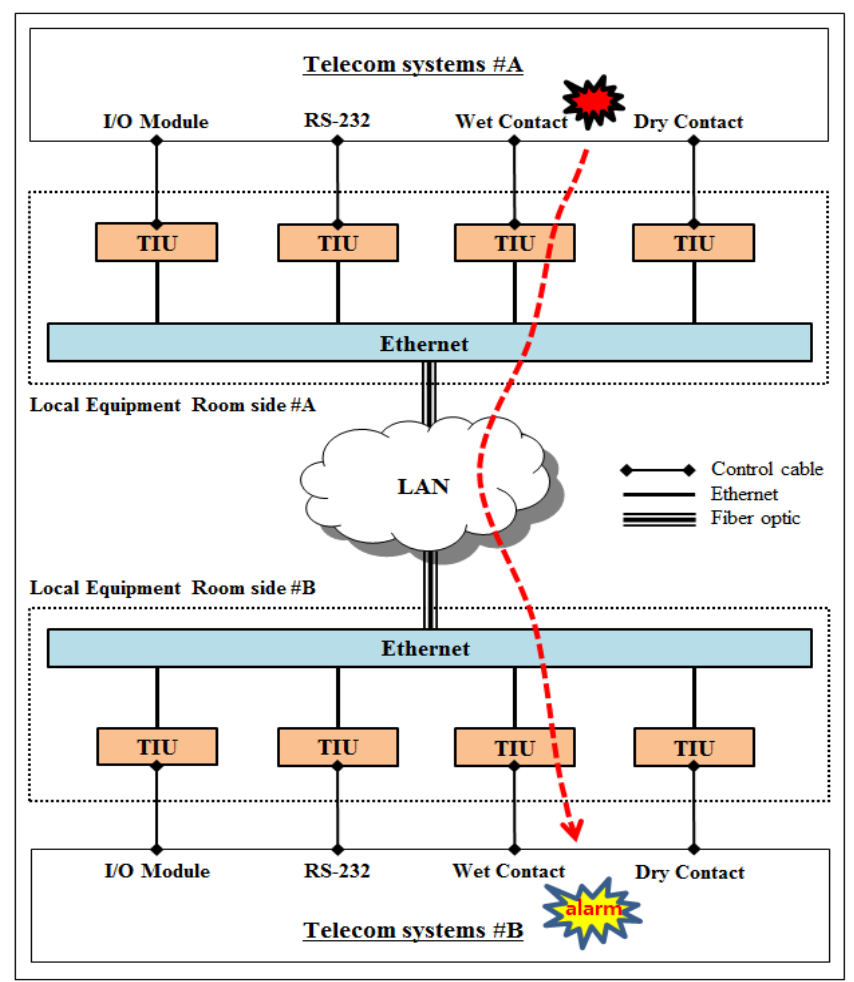

Fig. 4. Test-bed diagram for existing interfaces in telecom systems.

In the test-bed diagram for existing interfaces, it measures processing time from telecom systems \#A to telecom systems \#B.

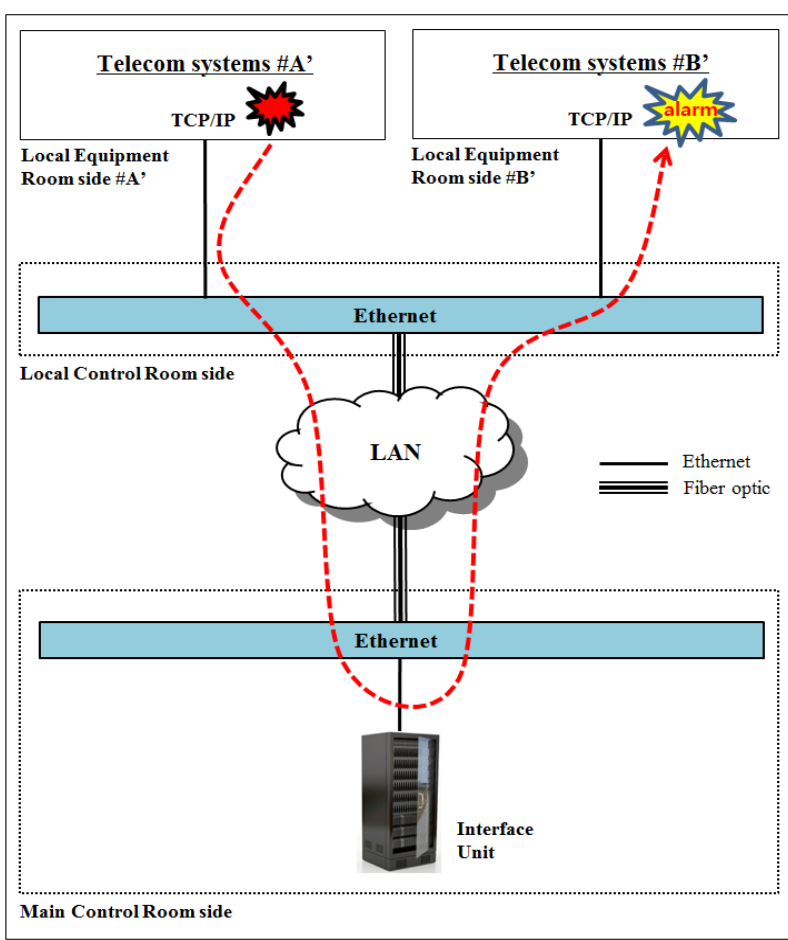

Fig. 5. Test-bed diagram for integrated interfaces in telecom systems.

In the test-bed diagram for integrated interfaces, it measures processing time from telecom systems \#A' through interface unit to telecom systems \#B'. Table IV shows the detailed specifications of the equipment used in the test.

TABLE IV: SPECIFICATION OF THE TEST-BED

\begin{tabular}{cl}
\hline \hline Division & \multicolumn{1}{c}{ Specification } \\
\hline Server & CPU : Intel Core i3 4170 \\
& Memory : DDR3 4GB \\
& Storage : SATA 500GB \\
& OS : Microsoft Windows 7 Professional DSP 32bit \\
& Database : MS-SQL Server 2008 R2 \\
& TIU Simulator \\
TIU & -Alarm Generator \\
& -Alarm Server Interface with MS-SQL Server \\
& -Alarm Client Module \\
S/W & Cisco, WS-C2960S-24PS-L \\
\hline \hline
\end{tabular}

\section{B. Test Results}

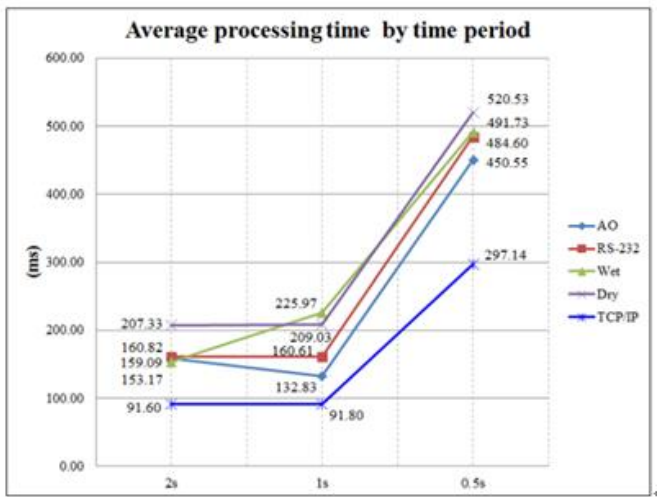

Fig. 6. Comparison of average processing time in data types by time phase 
Fig. 6 shows the average processing time measured for the intervals that generated alarms for different data types.

Overall, TCP/IP registered more excellent performance than the existing data type. At the alarm-generating interval of 2 seconds, TCP/IP registered average $185.7 \%$ improvement from the existing data type. It improved an average of average $198.4 \%$ at an interval of 1 second and average $163.9 \%$ at 0.5 seconds.

Fig. 7 shows the total average processing time measured for different data types.

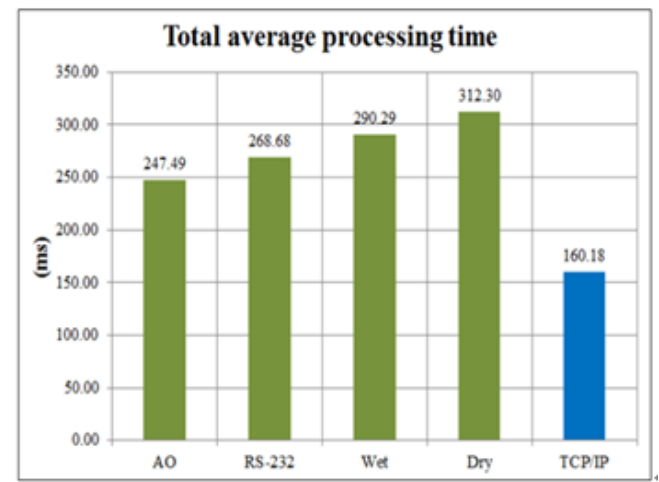

Fig. 7. Total average processing time in data types.

TCP/IP registered average $174.6 \%$ improvement in processing time from the existing data type. Integrated interfaces were not cause delay of processing time although interface unit. Rather, it is analyzed that processing time is delayed due to the TIU of existing interfaces.

This paper has proven with the test that the best performance is registered when TCP/IP is used as the standard data for the integrated interfaces for vessels' telecom systems.

\section{CONCLUSION}

This paper proposed integrated interfaces as a new implementation method by analyzing the issues with existing interfaces of telecom systems for vessels. The analysis and the test showed that data type standardization of telecom systems is needed to ensure development of ship technology. Furthermore, it is necessary to check interfaces of the vessel's the whole system for the next-generation ship.

\section{ACKNOWLEDGMENT}

This paper was supported by the Ministry of Trade, Industry and Energy, Korea, under the "Development of remote operation and management system based on telecom management system for offshore plant" support program (R0004783).

\section{REFERENCES}

[1] J. Kim, J. Son, and K. Yoon, "Improvement of the TMS deployment methods on ships and offshore plants (Abstract)," in Proc. ISMT 2016, p. 41, The Korea Society of Marine Engineering, November 2016.

[2] Chapter IV. Radiotelegraphy and radiotelephony, Chapter V. Safety of navigation, International convention for the safety of life at sea (SOLAS), IMO, November 1974.

[3] Regulation 18, Chapter V Safety of Navigation, Adoption of amendments to the international convention for the safety of lift at sea(SOLAS), 1974, As amended, Resolution MSC.99(73), Annex 7 , IMO, December 2000.

[4] Requirements for telecommunication systems, Telecom systems, T-001, NORSOK Standard, Edition 4, Standard Norway, pp. 9-10, February 2010.

[5] System 84, Telecommunication management system(TMS), Telecom systems, T-100, NORSOK Standard, Edition 4, Standard Norway, pp.51-54, February 2010.

[6] Scope, Telecom subsystems, T-100, NORSOK Standard, Edition 4, Standard Norway, pp. 7, February 2010.

[7] Amending council directive 96/98/EC on marine equipment, Commission directive 2011/75/EU, September 2011.

[8] Chapter VII Other life saving appliance, International lift-saving appliance(LSA) code, Resolution MSC.48(66), Treaty series No.44, IMO, June 1996.

[9] Chapter VII Other life saving appliances, Report of the maritime safety committee on its sixty-sixth session, MSC66 (24), IMO, June 1996.

[10] Rules for classification of ships, New buildings, Hull and equipment main class, "Hull equipment and safety, Part3, Chapter3, DNV, January 2010

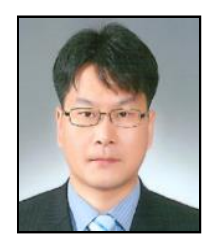

Jungwoo Kim received the M.S degree of computer engineering, Korea Maritime \& Ocean University, Busan, Korea in 2004. He works as an engineer at Hyundai Heavy Industries. His current research interests include telecommunication integration systems in vessels, super $\mathrm{Wi}-\mathrm{Fi}$, offshore engineering and indoor positioning services.

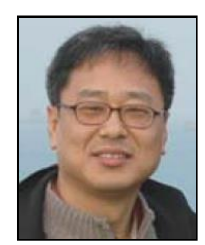

Jooyoung Son received his B.S. degree from Dept. of Computer Science, Seoul National University, Seoul, Korea in 1985, and his M.Eng. and Ph.D. from Dept. of Computer Engineering, Seoul National University in 1993 and 1998, respectively. He has worked for LG Electronics as a senior engineer from 1985 to 1998 . He has been a professor at Korea Maritime and Ocean University since 1998. His current research interests include high speed maritime data communication networks, telecommunication integration systems in vessels, maritime self-organizing networks, and indoor positioning services.

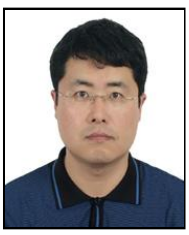

Kyoungkuk Yoon received the B.E. degree in Marine Engineering from Korea Maritime \& Ocean University in 1989. He received the M.E. and Ph. D.degrees from Korea Maritime University, Busan, Korea in 1997 and 2010. He works as a Director of R\&D Center at SeaNet Co., Ltd. His current research interests include power electronics, motor control and integrated communication system. 